\title{
EDITORIAL
}

\section{Are COPD patients with pneumonia who are taking inhaled corticosteroids at higher risk of dying?}

\author{
M.I. Restrepo*,\#, , E.M. Mortensen*,\#,+ and A. Anzueto ${ }^{\#, 9}$
}

I n 2007, CALVerley et al. [1] reported the results of the TORCH (Towards a Revolution in Chronic Obstructive Pulmonary Disease Health) study, which showed that combination of salmeterol (a long-acting $\beta$-agonist (LABA)) plus fluticasone propionate (an inhaled corticosteroid (ICS)) had a trend toward a lower all-cause mortality rate in patients with chronic obstructive pulmonary disease (COPD) compared with the placebo group, with a hazard ratio of 0.825 (95\% CI 0.68-1.002; $p=0.052)$. Despite the beneficial effects of ICS therapy in COPD patients, the results raised a possible safety issue regarding higher rate of community-acquired pneumonia (CAP) in the ICS groups. The probability of having pneumonia was higher among subjects receiving medications containing ICS (19.6\% for ICS plus LABA and $18.3 \%$ for ICS alone) compared with the placebo group $(12.3 \%$; $<<0.001)$ [1]. This association between ICS and pneumonia in COPD patients has also been seen in other studies: one study that examined the potential benefit of ICS and LABAs in reducing COPD mortality [1], and another comparing COPD exacerbation rates between patients receiving either salmeterol or the combination with a LABA $[2,3]$. A follow-up evaluation of the TORCH study identified several risk factors associated with pneumonia, including age $\geqslant 55 \mathrm{yrs}$, forced expiratory volume in $1 \mathrm{~s}$ $<50 \%$ predicted, COPD exacerbation in the year prior to the study, worse Medical Research Council dyspnoea score and body mass index $<25 \mathrm{~kg} \cdot \mathrm{m}^{-2}$. However, mortality rate due to pneumonia was not increased among subjects treated with ICS plus LABA, but the same could not be concluded for ICS monotherapy [4]. Therefore, it was suggested that ICS use increases the risk of CAP in COPD patients; however, the CAP severity event may be milder, and it is possible that these patients could have better clinical outcomes, as suggested by Malo de Molina et al. [5].

In this issue of the European Respiratory Journal, SINGANAYAGAM et al. [6] examine the issue of the impact of ICS use on outcomes in COPD patients with pneumonia. The authors conducted a prospective observational study of patients with

*Veterans Evidence-Based Research, Disseminations and Implementation Center, ${ }^{*}$ Audie L. Murphy Division, South Texas Veterans Health Care System, "Division of Pulmonary and Critical Care Medicine, and +Division of Hospital Medicine, Dept of Medicine, University of Texas Health Science Center at San Antonio, San Antonio, TX, USA.

CORRESPONDENCE: M.I. Restrepo, VERDICT (11C6), South Texas Veterans Health Care System ALMD, 7400 Merton Minter Boulevard, San Antonio, TX 78229, USA. E-mail: restrepom@ uthscsa.edu spirometry-confirmed COPD presenting with a primary diagnosis of CAP. Outcomes were 30-day and 6-month mortality, need for mechanical ventilation and/or inotropic support, development of complicated pneumonia, time to reach clinical stability, and length of hospital stay. Over a 5-yr period, the investigators enrolled 490 patients with COPD and CAP. Most patients $(76.7 \%)$ used ICS at the time of enrolment. According to the Global Initiative For Chronic Obstructive Lung Disease (GOLD) classification [7], most ICS users were stage III-IV. In contrast, more than half of non-ICS users were GOLD stage I-II. When ICS users were compared with non-ICS users, there were no statistically significant differences in outcomes, even after adjustment for COPD severity and Pneumonia Severity Index (PSI) score [8]. The authors concluded that prior ICS use was not associated with differences in clinical outcomes in COPD patients hospitalised with CAP.

The strengths of the study by SINGANAYAGAM et al. [6] are the prospective data collection design in a cohort of patients with spirometry-confirmed COPD, the stratification according to the GOLD guidelines, and CAP diagnosis by signs, symptoms and imaging studies. These are significant advances over prior studies of COPD patients and pneumonia. Another strength is the well-characterised cohort of hospitalised patients with CAP, with disease severity assessment at the time of clinical presentation using PSI [8] and CURB-65 scores (confusion, urea $>7 \mathrm{mmol} \cdot \mathrm{L}^{-1}$, respiratory frequency $\geqslant 30$ breaths $\cdot \mathrm{min}^{-1}$, systolic blood pressure $<90 \mathrm{mmHg}$ or diastolic blood pressure $\leqslant 60 \mathrm{mmHg}$, and age $\geqslant 65 \mathrm{yrs}$ ) [9]. In addition, the evaluation of a wide range of important clinical outcomes is meritorious.

The results observed by SingAnAYAGAM et al. [6] contrast with those we reported previously [5]. We used a US Dept of Veterans Affairs administrative cohort of hospitalised patients with pneumonia and assessed the association of ICS exposure with mortality [5]. Of 6,353 patients diagnosed with pneumonia and with a prior history of COPD, $38 \%$ were receiving ICS at the time of admission; multilevel regression models showed lower 30- and 90-day mortality (OR 0.76 (95\% CI $0.70-0.83$ ) and OR 0.80 (95\% CI $0.75-0.86)$, respectively) for outpatient ICS users. We concluded that these data suggested a potential beneficial effect, or at least not a deleterious effect, of the outpatient use of ICS in COPD patients who developed pneumonia. The major limitation of our study was that we did not have spirometric confirmation of COPD and lacked complete data for severity of illness adjustment. 
SINGANAYAGAM et al. [6] attempted to address several of these issues. Can we conclude that this study has addressed all of the methodological concerns to finally state that COPD patients who receive ICS and develop pneumonia do not have worse clinical outcomes? We believe there are several limitations that will require further research. First, the small sample size may be insufficient to detect a significant difference in mortality, as demonstrated by their small effect size and wide $95 \%$ confidence intervals. This is why most of the recently published large COPD studies included $\geqslant 6,000$ subjects.

Secondly, are all ICSs equal? The authors did not describe differences related to the type of ICS, duration of outpatient therapy, ICS dose prior to clinical presentation and their relationship with clinical outcomes. These data are crucial and their absence is an important limitation of the study. Furthermore, some studies suggested that there are differences related to the type of ICS and risk associated with CAP. A recent meta-analysis of individual patient data published by SIN et al. [10] suggested that budesonide treatment for 12 months did not increase the risk of pneumonia in COPD patients, contrary to the data published with fluticasone in the TORCH study [1].

Thirdly, the dose effect of ICS may impact on adverse events, as suggested by ERNST et al. [11], and was not described in the study by SINGANAYAGAM et al. [6]. ERNST et al. [11] described a two-fold increased risk of CAP-related hospitalisation with higher doses of fluticasone propionate $\left(\geqslant 1,000 \mu \mathrm{g} \cdot \mathrm{day}^{-1}\right)$.

In addition, several other issues need to be clarified. It is unclear why $23 \%$ of the patients in GOLD stage I-II received ICS. The GOLD guidelines recommend the use of ICS in patients in GOLD stages III-IV or patients with frequent exacerbations [7].

The authors also did not address the issue related to using systemic (oral or intravenous) corticosteroids at the time of clinical presentation, which is common practice in the real world. It is unclear if a significant bias favouring the patients that were receiving ICS was driven by the use of systemic corticosteroids when the COPD patients were admitted with pneumonia.

There is also no description of how many patients were continued on ICS during hospitalisation and/or were discharged on ICS. Relevant information regarding COPD patients who received long-acting anticholinergics, such as tiotropium, would have also strengthened the study. WEDZICHA et al. [3] assessed the relative efficacy of LABA plus ICS with the long-acting bronchodilator tiotropium in preventing COPD exacerbations and related outcomes in severe and very severe COPD patients. Beneficial effects were observed for the ICS plus LABA group, with better health status and lower death rate. However, more pneumonias were reported in the ICS plus LABA group compared with tiotropium (8 versus 4\%; $\mathrm{p}=0.008$ ). In addition, WELTE [12] assessed the efficacy of ICS plus LABA with tiotropium in patients eligible for ICS/LABA combination therapy. Those authors concluded that budesonide/formoteral with tiotropium versus tiotropium alone provided rapid and sustained improvements in lung function, health status, and morning symptoms and activities, and reduced exacerbations. There were only three cases of pneumonia within each treatment group $(<1 \%)$, which is consistent with prior studies [13-15].

Finally, the authors needed to address other variables that are associated with poor clinical outcome (i.e. mortality), such as microbiology, appropriate/adequate antibiotic therapy, prior influenza, pneumococcal vaccination, etc.

Although there is some evidence that ICS use in COPD patients may increase the incidence of CAP, most studies have failed to show an impact on outcomes. Clinicians should use these medications judiciously and, at the same time, be aware that the frequency of CAP may be increased. However, we can be reassured that there is little support for the hypothesis that ICS use associated with CAP increases mortality risk in COPD patients. Additional research is needed to address the limitations of this and other studies, and to determine the safety profile of ICS in COPD patients.

\section{SUPPORT STATEMENT}

M.I. Restrepo's research time is partially protected by Award Number K23HL096054 from the National Heart, Lung and Blood Institute. The content is solely the responsibility of the authors and does not necessarily represent the official views of the National Heart, Lung, and Blood Institute or the National Institutes of Health (Bethesda, MD, USA). The funding agencies had no role in the preparation, review or approval of the manuscript. The views expressed in this article are those of the authors and do not necessarily represent the views of the Dept of Veterans Affairs or the University of Texas Health Science Center at San Antonio (San Antonio, TX, USA).

\section{STATEMENT OF INTEREST}

Statements of interest for all authors can be found at www.erj. ersjournals.com/site/misc/statements.xhtml

\section{REFERENCES}

1 Calverley PMA, Anderson JA, Celli B, et al. Salmeterol and fluticasone propionate and survival in chronic obstructive pulmonary disease. $N$ Engl J Med 2007; 356: 775-789.

2 Kardos P, Wencker M, Glaab T, et al. Impact of salmeterol/ fluticasone propionate versus salmeterol on exacerbations in severe chronic obstructive pulmonary disease. Am J Respir Crit Care Med 2007; 175: 144-149.

3 Wedzicha JA, Calverley PM, Seemungal TA, et al. The prevention of chronic obstructive pulmonary disease exacerbations by salmeterol/fluticasone propionate or tiotropium bromide. Am J Respir Crit Care Med 2008; 177: 19-26.

4 Crim C, Calverley PMA, Anderson JA, et al. Pneumonia risk in COPD patients receiving inhaled corticosteroids alone or in combination: TORCH study results. Eur Respir J 2009; 34: 641-647.

5 Malo de Molina R, Mortensen EM, Restrepo MI, et al. Inhaled corticosteroid use is associated with lower mortality for subjects with COPD and hospitalised with pneumonia. Eur Respir J 2010; 36: 751-757.

6 Singanayagam A, Chalmers JD, Akram AR, et al. Impact of inhaled corticosteroid use on outcome in COPD patients admitted with pneumonia. Eur Respir J 2011; 38: 36-41.

7 Rabe KF, Hurd S, Anzueto A, et al. Global strategy for the diagnosis, management, and prevention of chronic obstructive pulmonary disease: GOLD executive summary. Am J Respir Crit Care Med 2007; 176: 532-555.

8 Fine MJ, Auble TE, Yealy DM, et al. A prediction rule to identify low-risk patients with community-acquired pneumonia. $N$ Engl J Med 1997; 336: 243-250. 
9 Lim WS, Lewis S, Macfarlane JT. Severity prediction rules in community acquired pneumonia: a validation study. Thorax 2000; 55: 219-223.

10 Sin DD, Tashkin D, Zhang $X$, et al. Budesonide and the risk of pneumonia: a meta-analysis of individual patient data. Lancet 2009; 374: 712-719.

11 Ernst P, Gonzalez AV, Brassard P, et al. Inhaled corticosteroid use in chronic obstructive pulmonary disease and the risk of hospitalization for pneumonia. Am J Respir Crit Care Med 2007; 176: $162-166$

12 Welte T. Acute exacerbation of chronic obstructive pulmonary disease: more a functional than an inflammatory problem? Am J Respir Crit Care Med 2008; 177: 130-131.
13 Calverley PM, Boonsawat W, Cseke Z, et al. Maintenance therapy with budesonide and formoterol in chronic obstructive pulmonary disease. Eur Respir J 2003; 22: 912-919.

14 Tashkin DP, Rennard SI, Martin P, et al. Efficacy and safety of budesonide and formoterol in one pressurized metered-dose inhaler in patients with moderate to very severe chronic obstructive pulmonary disease: results of a 6-month randomized clinical trial. Drugs 2008; 68: 1975-2000.

15 Rennard SI, Tashkin DP, McElhattan J, et al. Efficacy and tolerability of budesonide/formoterol in one hydrofluoroalkane pressurized metered-dose inhaler in patients with chronic obstructive pulmonary disease: results from a 1-year randomized controlled clinical trial. Drugs 2009; 69: 549-565. 